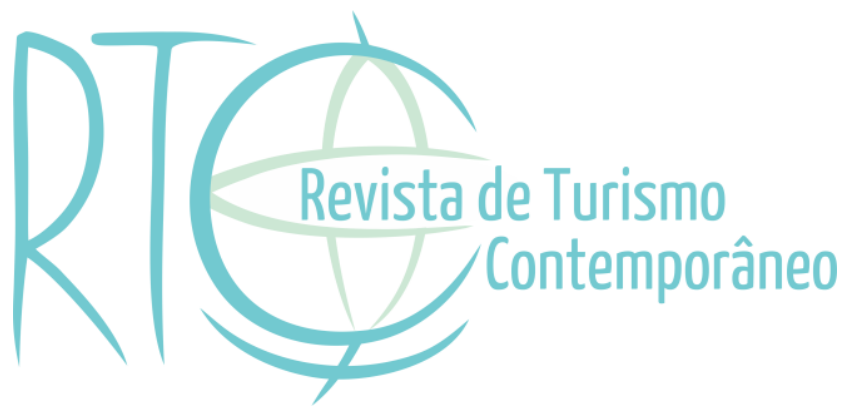

\title{
Pluralismo relacional como influenciador de ações de responsabilidade social corporativa de uma rede de pequenas empresas do setor hoteleiro
}

Relational pluralism as an influencer of corporate social responsibility actions of a network of small companies in the hotel sector

Paula Maines da Silva

Docente dos cursos de Pós-Graduação de Educação a Distância em Gestão da Universidade Luterana do Brasil - ULBRA, Canoas/RS, Brasil

E-mail: paulam@cpovo.net

Artigo recebido em: 25-06-2018

Artigo aprovado em: 21-12-2018 


\section{RESUMO}

O pluralismo relacional ocorre quando empresas derivam o seu significado e suas ações a partir das relações com vários tipos de entidades. Nesse sentido, as pequenas empresas que atuam de forma conjunta, por meio de redes, podem ser influenciadas pelas múltiplas relações no desenvolvimento de estratégias coletivas de responsabilidade social corporativa (RSC), buscando, assim, sanar problemas socioambientais em seu entorno. Dessa maneira, o presente trabalho teve como objetivo geral compreender como o pluralismo relacional influenciava pequenas empresas em suas estratégias coletivas de responsabilidade social corporativa. $\mathrm{O}$ estudo focou em pequenas empresas do setor hoteleiro que eram associadas de uma rede. Em relação aos aspectos metodológicos, esta pesquisa teve caráter qualitativo e utilizou a análise do discurso. Como resultados de pesquisa, concluiu-se que o pluralismo relacional influencia pequenas empresas em suas estratégias coletivas de responsabilidade social corporativa. Esse fato se instala em razão do relacionamento com distintos atores que se detectam dentro da rede, entre todos os associados e também com os que se encontram fora da rede, como Sindicatos de Hotéis, Bares e Restaurantes, entre outros.

Palavras-chave:Pluralismo Relacional. Estratégias Coletivas. Responsabilidade Social Corporativa.

\section{ABSTRACT}

Relational pluralism occurs when companies derive their meaning and actions from relationships with various types of entities. In this sense, small companies acting jointly through networks can be influenced by the multiple relationships in the development of collective strategies of corporate social responsibility (CSR), seeking to remedy social and environmental problems in their environment. In this way, the present work had as general objective to understand how the relational pluralism influenced small companies in their collective strategies of corporate social responsibility. The study focused on small hotel companies that were associated with a network. Regarding the methodological aspects, this research was qualitative and used the discourse analysis. As research results, it was concluded that relational pluralism influences small companies in their collective strategies of corporate social responsibility. This is due to the relationship with different actors that are detected within the network, among all associates and also with those outside the network, such as hotel, restaurant and restaurant unions, among others.

Keywords: Relational Pluralism. Collective Strategies. Corporate Social Responsibility. 


\section{INTRODUÇÃO}

Os problemas ambientais e sociais são questões que fazem parte desta sociedade e estão incorporados no mundo dos negócios. As empresas estão incluindo a dimensão socioambiental na gestão como forma de apresentar resultados aos clientes, acionistas, fornecedores, à sociedade em geral e a outros atores envolvidos. Os temas relacionados à Sustentabilidade e ao Desenvolvimento Sustentável, assim como a Responsabilidade Social Corporativa (RSC) estão tendo mais atenção e interesse dos estudiosos, das escolas de negócios e das empresas modernas em virtude do aumento da consciência por questões relacionadas à ética, à degradação ambiental e aos direitos humanos. (Doh \& Tashman, 2014; Sharma, Surya \& Mehta, 2012).

Os problemas ambientais que foram surgindo estão na maioria deles relacionados com a decorrência de fatores econômicos. A proposta da RSC é a de que as organizações desempenhem um papel social além do econômico e que contribuam, de forma positiva, para o desenvolvimento sustentável das localidades. Isso não significa que as empresas devam esquecer o seu foco - o lucro, mas que possam identificar oportunidades de negócios que envolvam a sustentabilidade, gerando, assim, retorno aos investidores e soluções às necessidades sociais. Essa proposta está alinhada à criação de valor compartilhado (CVC), como apontam Porter e Kramer (2011), cujas políticas e práticas operacionais aumentam a competitividade de uma empresa, enquanto avançam simultaneamente as condições econômicas e sociais nas comunidades em que atuam.

Esse tipo de atividade que visa à melhoria dos aspectos socioambientais, normalmente é desenvolvido por grandes organizações, pois as pequenas e médias empresas (PME) não conseguem desenvolver tais ações sozinhas de forma a gerar um grande impacto nas localidades. Para suprir essa questão, há iniciativas de impacto coletivo, ou seja, são os compromissos a longo prazo de um importante grupo de atores, de diferentes setores com uma agenda comum e que almeja a solução de um problema social específico. As ações são apoiadas por um sistema de medição compartilhada e se reforçam mutuamente em uma comunicação contínua e por uma organização que fornece suporte à coordenação e à infraestrutura necessária ao desenvolvimento de tais ações. (Kania \& Kramer, 2011).

A abordagem coletiva pode ser aplicada a fim de resolver diversas questões em nível local, nacional e até mesmo global, pois não há outra forma da sociedade alcançar um progresso em larga escala, com problemas tão complexos e urgentes na forma como as empresas estão tentando resolvê-las, de forma independente. (Hanleybrown, Kania, \& 
Kramer, 2012). Assim, a maneira como as PMEs podem conseguir gerar esses impactos positivos é através da utilização de estratégias coletivas, consideradas formas cooperadas de trabalho em detrimento do trabalho individual. Utilizados como forma de concorrer no mercado e enfrentar a competição das grandes empresas que apresentam uma gama de recursos e estruturas que as PMEs não possuem.

As estratégias coletivas são utilizadas quando as empresas se associam em redes que compreendem, segundo Provan, Fish e Sydow (2007), um conjunto de três ou mais empresas conectadas de modo a atingir um objetivo comum, como por exemplo, ações de responsabilidade social corporativa. Nesse tipo de configuração empresarial, se encontram as redes horizontais, abrangendo um grupo de empresas que atuam na mesma fase de uma cadeia produtiva, realizando, em conjunto, atividades comuns ao grupo ou atuando de forma complementar. (Roth et al., 2012).

As empresas associadas de uma mesma rede são influenciadas pelas relações que mantêm com diferentes atores, incluindo representante de empresas, Organizações não Governamentais (ONGs), instituições acadêmicas, clientes, dentre outros. Essas relações geram um pluralismo relacional que ocorre quando uma entidade central (empresa) estabelece o seu significado e suas ações a partir das relações com vários tipos de entidades. (Shipilov et al., 2014). O pluralismo relacional é uma perspectiva contemporânea de analisar as redes e seus associados a partir dos vários tipos de relações com outros atores os quais possibilitam múltiplas identidades e o que as tornam únicas. Sendo assim, esta tese teve como tema de pesquisa o pluralismo relacional, estratégias coletivas em redes e responsabilidade social corporativa.

Nesse contexto, objetivo geral da pesquisa foi de compreender como o pluralismo relacional influencia uma rede de pequenas empresas em suas estratégias coletivas de responsabilidade social corporativa. Para isso foi realizada a pesquisa com um grupo de hotéis de pequeno porte que se reuniu para estruturar uma associação denominada Roteiros de Charme, que se constitui como uma entidade privada e sem fins lucrativos, fundada em 23 de junho de 1992. Há 66 pequenos e médios hotéis, pousadas e refúgios ecológicos em 16 Estados e 55 destinos turísticos, situados de norte a sul no Brasil. Os hotéis localizam-se em áreas de conservação e em ecossistemas frágeis, como o Cerrado, a Mata Atlântica e o Pantanal. Isso demonstra a importância de um contínuo e sólido programa ambiental voltado à sustentabilidade do meio ambiente, dos destinos turísticos e das comunidades onde operam. A proposta da associação é promover novos destinos turísticos, garantindo, assim, uma 
hospedagem que promova a formação e fixação de uma comunidade profissionalmente mais capacitada e mais saudável, evitando o êxodo para os grandes centros. (Roteiros de Charme, 2016).

O artigo sistematiza-se, inicialmente, com uma breve revisão da literatura sobre o tema, abordando sustentabilidade e responsabilidade social corporativa no contexto empresarial; estratégias coletivas em redes; pluralismo relacional; seguindo com a descrição da metodologia adotada. Posteriormente, apresentam-se a discussão dos resultados, as considerações finais e as referências utilizadas.

\section{REVISÃO DA LITERATURA}

Os problemas ambientais e sociais estão sendo incorporados constantemente no mundo dos negócios. Com isso, as empresas, cada vez mais, congregam a dimensão socioambiental na gestão também como forma de apresentar resultados positivos aos clientes, aos acionistas, fornecedores, ou seja, à sociedade em geral.

Segundo Van Marrewijk (2003), as ideias de sustentabilidade e RSC são vistas ora como sinônimos, ora como termos distintos, justamente por serem conceitos elaborados a partir do conceito de desenvolvimento sustentável, cidadania corporativa, empreendedorismo sustentável, triple bottom line, ética nos negócios e RSC. Desse modo, como apontou Strand, Freeman e Hockerts (2015), normalmente o conceito de sustentabilidade é visto com foco apenas nas questões ambientais, enquanto a RSC se aplica ao aspecto social, o que leva à necessidade de discutir a visão de cada conceito a partir dos estudos de autores renomados nessa área.

Bansal e Desjardine (2015) e Doh e Tashamn (2014) argumentaram em seus estudos que a comissão mundial do meio ambiente e desenvolvimento divulgou, em 1987, um documento em que a definição de sustentabilidade abrangia a satisfação das necessidades do presente sem comprometer a capacidade das gerações futuras no que tange à satisfação de suas próprias necessidades, através do uso equilibrado dos recursos e suprimentos ao longo do tempo.

A partir desse panorama, o tema se tornou ponto frequente de debates, chegando assim, às organizações. Em 2005, por exemplo, Blindheim e Langhelle (2010) afirmaram que a Assembleia Geral das Nações Unidas reconheceu o desenvolvimento econômico, desenvolvimento social e proteção ambiental como os três pilares do desenvolvimento sustentável e que compõe a "triple bottom line". 
Pelo desenvolvimento de ações ambientais e sociais, não é fácil chegar a uma definição de responsabilidade social corporativa, segundo Gatti e Seele (2014). As várias definições para RSC incluem desenvolvimento econômico, práticas éticas, proteção ambiental, stakeholders, participação, transparência, responsabilidade, comportamento responsável e obrigação moral. (Rahman, 2011; Williams, 2014). As investigações sobre sustentabilidade visam à elucidação do que o conceito se propõe; os estudos sobre a RSC também expressam esta ambição tendo em vista a união dos fatores ambientais e sociais, como já expressos nessa pesquisa.

Um dos conceitos mais antigos sobre RSC, segundo Davis (1973), é que a responsabilidade social corporativa trata da consideração das empresas que respondem outras questões além dos aspectos econômicos, técnicos e requisitos legais. Metcalf e Benn (2012) e Morhardt (2010) apontam esse entendimento como atividades sociais que antecedem as decisões dos negócios; a RSC refere-se ao compromisso de uma organização em adotar práticas responsáveis de negócios na tentativa de amparar o desenvolvimento a longo prazo.

Outra visão do assunto é a de Herrmann (2004), porque ele acredita que os aspectos relevantes da sustentabilidade estão inseridos na RSC, uma vez que as empresas não são entidades autocentradas apenas em gerar lucros, mas que têm relação direta com as ações que ocorrem na economia, sociedade e ambiente. Por entender que as organizações existem para atender as demandas dos seus stakeholders, elas abrangem acionistas, clientes, funcionários, fornecedores, sociedade e ambiente no que se refere à geração de lucro, movimentação da economia e melhoria dos aspectos socioambientais. $\mathrm{O}$ conceito que mais representa esta ideia é o da responsabilidade social corporativa proposto por Herrmann (2004). Dessa forma, ao longo do trabalho, a RSC pode ser compreendida como algo que abrangem os aspectos econômicos, sociais e ambientais desenvolvidos pelas organizações.

O trabalho em rede está cada vez mais sendo empregado por empresas que querem manter uma vantagem competitiva e que o trabalho pode estar aliado ao desenvolvimento de atividades socioambientais. $\mathrm{O}$ trabalho em conjunto das organizações traz à tona o conceito de estratégia cooperativa ou coletiva. (Astley \& Fombrun, 1983; Astley, 1984). De acordo com Astley e Fombrun (1983, p. 580), as estratégias coletivas são “[...] uma resposta sistêmica por um conjunto de organismos que colaboram para absorver a variação apresentada pelo ambiente interorganizacional", ou seja, as estratégias coletivas são reflexos da necessidade das organizações em promoverem ações cooperadas a fim de que se protejam e sobrevivam no mercado. 
Essa abordagem identifica um papel diferenciado sobre o desempenho das organizações como membros integrantes de uma coletividade em rede. (Astley \& Fombrun, 1983). Entende-se que essas organizações não são atores independentes que se localizam em seus respectivos ambientes unicamente, mas sim, componentes deles. Essa percepção exige que os gestores tenham uma visão de grupo, uma vez que eles já não podem se firmar somente como agentes autônomos, pois, dessa forma, as empresas passariam a desenvolver um processo de negociação e troca com seus pares por meio do qual cada uma das partes teria que, voluntariamente, desistir de alguma condição em troca de concessões por parte dos outros. (Benson, 1975; Astley, 1984; Barnett, Mischke, \& Ocasio, 2000).

Ao desenvolver estratégias coletivas, as empresas obtêm ganhos que podem ser observados a partir de situações do ambiente mercadológico e que abrangem o crescimento de soma positiva, o maduro de soma zero, o declínio de soma negativa e a transformável para crescimento de soma positiva. A soma positiva, a soma zero e a soma negativa são provenientes da teoria dos jogos desenvolvidos em 1944 por Von Neumann e Morgenstern (Brandenburger \& Nalebuff, 1995).

Em um jogo de soma positiva, é possível que todos os jogadores aumentem o tamanho dos benefícios que recebem jogando, ou seja, todos os jogadores podem ganhar; em soma zero, o tamanho do ganho permanece o mesmo ao longo do tempo de tal forma que, para um jogador ganhar mais recompensas, outro jogador deve perdê-las; no de soma negativa, o tamanho do ganho diminui ao longo do tempo e, assim, um jogador, apenas para manter o que tem, precisa que o outro perca. (Nielsen, 1988).

O objetivo das empresas se unirem a outras para um trabalho coletivo é a obtenção de benefícios a fim de que todos saiam ganhando. Porém, por outro ângulo, ao implantar estratégias coletivas, não significa que a competição entre as empresas deixe de existir. Há, pois, momentos de turbulência do mercado e as organizações, nesse momento, optam por trabalhar com as estratégias coletivas; em outros momentos, quando surgirem disfunções que atrapalhem a gestão ou a flexibilidade estratégica, as empresas optam pela competição. Assim, com esses conceitos, intui-se que há essas duas perspectivas em discussão.

A abordagem do trabalho coletivo em redes pode provocar uma explicação não somente por que as empresas criam laços e a intensidade deles no desenvolvimento da RSC, mas também os dados explicam a multiplicidade das relações que ocorrem em uma rede para desenvolvimento da responsabilidade social corporativa. Essa abordagem pode ser vista a 
partir do pluralismo relacional que analisa as redes e as relações que ela mantém com diferentes indivíduos.

As organizações, como sistemas adaptativos complexos, são imbricadas em redes heterogêneas que se consistem de diferentes tipos de relações com pessoas, projetos, máquinas, edifícios, etc. O pluralismo relacional é definido por Shipilov et al. (2014) como a extensão que uma entidade focal (uma pessoa, um grupo ou uma organização) deriva o seu significado a partir das relações que mantém com outras entidades. Ele analisou como se processam as relações na rede e as suas implicações, diferente dos estudos sobre laços que possuem o foco apenas na intensidade dos mesmos.

O pluralismo relacional pode ser caracterizado de três formas, denominadas de multiplex, heterogeneous e overlapping. A primeira, as relações multiplex são fundamentadas na teoria das redes sociais, cujos atores estão ligados por mais de uma teia de relações como, por exemplo, colegas de trabalho que também são amigos, irmãos trabalhando em um negócio juntos e cônjuges pertencentes, quem sabe, a diferentes partidos políticos. (Kuwabara, Luo, \& Sheldon, 2010). Para ser configurada uma relação multiplex, Tuuli, Koh e Phua (2012) afirmam que os atores precisam de interações repetidas, mantendo sempre os mesmos ou diferentes papéis, ações e filiações.

As relações heterogeneous, de acordo com Gulati et al. (2010), é quando os atores formam conexões com outras pessoas de origens muito diferentes, como, por exemplo, diferentes etnias ou diferentes indústrias. Este tipo de relação está enraizada na teoria da identidade social, a qual explica as categorizações que os indivíduos usam para decretar seu sentimento de pertencimento com determinados grupos e que reforça a sua própria concepção. (Ashforth \& Mael, 1989; Tajfel \& Turner, 1985). Essa relação indica a formação de relações homogêneas em vez de heterogêneas, mas alguns pesquisadores, como Alvesson, Ashcraft e Thomas (2008), Ashforth (1998), Gioia, Schultz e Corley (2000) e Gioia et al. (2010), enfatizam o caráter dinâmico do mundo social, salientando que a identidade é temporária e sensível ao contexto.

A última forma são as relações overlapping que possuem como base o capital social (Gulati et al., 2010) e são caracterizadas pelas redes fechadas, ou seja, há uma quantidade de laços uns aos outros, criando cliques densamente conectados. $\mathrm{Na}$ visão de Kuwabara, Luo e Sheldon (2010), a configuração de redes fechadas pode facilitar a formação de múltiplas relações, na medida em que os atores em tríades fechadas interagem com mais frequência e realizam trocas mais amplas entre si. Essa estrutura de rede promove confiança 
entre os atores envolvidos no processo e, a partir dos relacionamentos, reforçam suas semelhanças, além de fornecer verificações estruturais contra fraude e má-fé.

As organizações individuais e as redes estão rodeadas com o pluralismo relacional, pois as relações com diferentes atores fazem parte do dia a dia do ambiente organizacional. Apesar de ser um aspecto presente nas práticas das empresas, os estudos sobre esta temática ainda podem avançar, uma vez que ainda há diversas lacunas, principalmente sobre as identidades dos agentes econômicos e a heterogeneidade nas suas relações, contribuindo, então, para a compreensão das dinâmicas das redes e as suas consequências no desempenho. Os estudos, nesse sentido, sobre o pluralismo relacional em redes devem ser estendidos, principalmente para ampliar a compreensão, cada vez mais, salientando como as múltiplas relações acabam influenciando as empresas na definição de estratégias conjuntas.

\section{METODOLOGIA}

A pesquisa desenvolvida trata-se de uma pesquisa exploratória que, segundo Collis e Hussey (2005, p. 24), é realizada quando “[...] há poucos ou nenhum estudo anterior em que possamos buscar informações sobre a questão ou o problema”. Assim, é possível compreender melhor o fenômeno estudado uma vez que as pesquisas exploratórias "[...] têm como propósito proporcionar maior familiaridade com o problema, com vistas a torná-lo mais explícito ou a construir hipóteses" (Gil, 2010, p. 27).

A pesquisa empírica teve como objeto de estudo uma associação de hotéis que trabalha em rede, denominada de Roteiros de Charme. A rede é formada por 66 pequenas empresas de hotéis, pousadas e refúgios ecológicos situados de norte a sul no Brasil, em 16 Estados e 55 destinos turísticos. A escolha se deve ao fato de as empresas associadas contarem com administração independente e também porque os empreendimentos destacamse pelo desenvolvimento da responsabilidade socioambiental, de forma economicamente viável e sustentável.

Para a realização do estudo, coletaram-se os dados primários e os secundários. Os dados primários foram reunidos através de entrevistas que têm como suporte um protocolo de pesquisa; os dados secundários se constituíram em materiais disponibilizados pela Associação e pelos hotéis tais como materiais de divulgação dos hotéis e o código de ética e conduta ambiental.

As entrevistas foram organizadas de forma não estruturadas, pois elas permitem que o entrevistador exercite sua iniciativa no acompanhamento da resposta a uma das 
questões. Os assuntos não previstos antecipadamente podem ser incluídos no roteiro. Conforme Creswell (2010, p. 214), as entrevistas qualitativas envolvem as "[...] questões não estruturadas e em geral, abertas, que são em pequeno número e se destinam a suscitar concepções e opiniões dos participantes".

O protocolo de pesquisa é um instrumento que garante maior confiabilidade e validade aos dados coletados, obtidos por meio de entrevistas, interações, observações pessoais, conversas informais, participações em eventos ou reuniões e relatórios ou arquivos da organização. (Voss, Tsikriktsis, \& Frohlich, 2002). Esse documento foi validado, antes de ser aplicado junto aos entrevistados, por dois especialistas, professores da área de administração, sendo que um deles possui expertise na área de relações interorganizacionais e o outro na área socioambiental.

A entrevista com a direção da Associação propôs evidenciar os mesmos tipos de questões que são direcionadas aos hotéis e pousadas cuja finalidade foi compreender e validar as informações coletadas com os 24 gerentes e proprietários dos hotéis associados.

$\mathrm{O}$ agendamento das entrevistas se desenvolveu por e-mail ou por telefone de setembro a novembro de 2016. Inicialmente se identificou ou o proprietário ou o gerente da empresa para um primeiro contato. Em seguida, encaminhou-se uma carta de apresentação ao responsável, já identificado, juntoao convite a fim de que ele participasse da pesquisa. $\mathrm{Na}$ carta, elencaram-se dados tais como, o objetivo da mesma, o tempo de duração e já se estipulava, na ocasião, uma data para a realização da atividade. Além dos hotéis, também se realizou uma entrevista com um dos diretores da associação Roteiros de Charme.

Os dados foram analisados usando-se a análise de conteúdo das entrevistas, que é um "[...] conjunto de técnicas de análise de comunicações”. (Bardin, 1977, p. 31). Para isso, usou-se a técnica na interpretação das entrevistas, que "[...] visa, principalmente, a analisar e comparar o conteúdo do conhecimento do especialista" (Flick, 2009, p. 158). Analisou-se o conteúdo das perguntas abertas, possibilitando identificar as ideias centrais dos respondentes. Nessa atividade, seguiram-se as três etapas propostas por Bardin (1977) que compreende a pré-análise, exploração do material e tratamento dos resultados, inferência e interpretação.

Na pré-análise realizam-se a organização dos materiais coletados, leitura geral das evidências e definição dos procedimentos a serem seguidos. Na etapa de exploração do material é realizada a implementação dos procedimentos, ou seja, os elementos de cada entrevista e de cada caso são codificados. A codificação corresponde a "[...] uma transformação - efetuada segundo regras precisas - dos dados brutos do texto, transformação 
esta que, por recorte, agregação e numeração, permite atingir uma representatividade do conteúdo". (Bardin, 1977, p. 103).

E, na etapa de tratamento dos resultados, inferências e interpretações, avaliam-se as informações a partir de uma análise comparativa das categorias, observando, assim, aspectos semelhantes e os concebidos de maneiras diferentes.

\section{DISCUSSÃO DOS RESULTADOS}

Buscou-se identificar com quem as pousadas e hotéis se relacionavam mais frequentemente dentro e fora da rede. Dentro da rede, a relação é com os associados de uma forma geral, pois possuem um canal de comunicação informal (WhatsApp) entre todos os associados; os relacionamentos fora da rede foram mencionados, na grande maioria, na participação em outras entidades como Sindicatos de Hotéis, bares e restaurantes, Convention Bureaus, Conselhos de Turismo e Sindicatos Patronais. Alguns hoteleiros, além das organizações mencionadas anteriormente, ainda participam de outras entidades do setor de turismo e hotelaria tanto em nível nacional como internacional. Eles estabelecem parcerias comerciais e alguns proprietários integram alguma organização não governamental ou conselho de entidades locais. Outras relações são estabelecidas também como as mencionadas pelo entrevistado 8 ao comentar:

Possuímos quase $70 \%$ dos funcionários que são aqui do Estado, também nos
relacionamos com a parte política que devemos estar envolvidos, apesar de ser
delicado e complicado, mas precisamos operar com eles. Com os fornecedores, no
qual buscamos fazer uma seleção de produtos, quando dá. E também com a
comunidade, pois já fizemos muitos projetos na área social. (Entrevistado 8)

Após a identificação com quem eram estabelecidos os relacionamentos das pousadas e hotéis, verificou-se como cada empresa definia as suas estratégias de responsabilidade social corporativa. Algumas empresas não possuíam um planejamento formal como desenvolve o entrevistado 2, ao afirmar que:

Não temos um planejamento específico. O Hotel tem 15 anos e desde o início procura o fortalecimento com os fornecedores. Na questão ambiental já existia a preocupação desde antes do ingresso no roteiro do charme, em 2008. O hotel possui 70 hectares com preservação da mata, no qual biólogos fizeram catalogação das espécies ao longo da trilha da mata, além de fazermos uma adequação na preservação de espécies inadequadas e ou espécies em extinção. Na iluminação, vem sendo feita troca por lâmpadas de led, bem como a separação de resíduos, destinação do óleo de cozinha, preocupação com a lavagem de toalhas e o ingresso do material no meio ambiente. Algumas campanhas com funcionários são realizadas para economia da iluminação e evitar o desperdício da água. E também fazemos a devolução de materiais aos produtores para reutilização e a consequente menor produção de lixo. Possuímos uma horta orgânica, para produção própria dos vegetais e temperos e fornecemos aos clientes uma muda de lavanda no check out. (Entrevistado 2) 
O entrevistado 3 também informou que "não há uma formalização das ações. Algumas delas são sugeridas pela consultoria da rede, durante as vistorias e outras realizadas de forma automática no dia a dia". O entrevistado 24 corrobora que algumas ações são definidas pela rede, ao mencionar que "a própria associação exige pré-requisitos de seus associados para que seja um membro. Passam-se por visitas periódicas, onde nosso padrão e o padrão da associação são mantidos rigorosamente. Dentre essas estratégias, a sustentabilidade, nossa e do entorno". Essa mesma visão de como é definida as ações de RSC foi comentada pelo entrevistado 22 que "é feita uma consultoria da rede quanto às questões ambientais. São recomendações que são dadas e podem ser aplicadas no dia a dia do hotel, como coleta da água, reaproveitamento do óleo, coleta seletiva, criação de horta no hotel. Ter $85 \%$ de mão de obra local”.

Outra questão levantada pelo entrevistado 8 é a crise atual, que acaba inibindo o desenvolvimento de ações voltadas para os aspectos ambientais e sociais. O mesmo comentou que "com a crise tenho feito pequenas ações na pousada, como sinalização nas trilhas, pequenas ações com a comunidade, como por exemplo, brindes para o bingo, além de alguns ajustes legais como o sinalizado pelos bombeiros no que se refere à distribuição de gás".

O entrevistado 6 menciona uma formalização das ações ao afirmar que:

No mês de outubro e novembro elaboramos as ações do ano seguinte, colocando meta de faturamento, atualização do hotel. Temos 30 e poucos itens de sustentabilidade e isso inclui uma ação para tornar o resíduo do vidro em pó, troca das lâmpadas por led, e alguns procedimentos operacionais padrões que envolvem ações sociais, como festa dos funcionários, no mês das crianças fazer festa para os filhos dos funcionários, visita das crianças da comunidade ao hotel e cursos diversos para os funcionários. (Entrevistado 6)

Já o entrevistado 23 declara que "as questões ambientais já estão postas, por isso as ações desenvolvidas visam reduzir consumo de energia".

A forma como os associados abordam o modo de cada um definir as suas estratégias de responsabilidade social corporativa evidencia que as empresas não usam a RSC como discurso (Soares, 2004) para atender acionistas, proprietários e demais stakeholders, como ocorre muitas vezes em grandes corporações, e nem entram em discussões sobre a conveniência ou não da empresa em adotar ações sociais. As pousadas e hotéis já possuem consciência do seu papel na sociedade e a forma de como produzir bem-estar. Assim, as questões socioambientais estão incorporadas naturalmente no negócio, sendo desenvolvidas ações de menor até maior complexidade. 
A partir da verificação da forma como as pousadas e hotéis definem as estratégias de RSC, passou-se a verificar de que forma a relação com os stakeholders influenciam nessas estratégias. Nesse sentido, $8 \%$ das pousadas e hotéis mencionaram que não sofrem nenhuma influência por parte dos stakeholders, enquanto 92\% foram unânimes de que a rede é quem influencia, através da avaliação e reavaliação dos procedimentos, além do código de conduta ambiental que acaba intervindo nas ações do hotel, conforme mencionado pelo entrevistado 3. Já o entrevistado 9, aponta que "a associação tem grande influência na medida em que trazem sugestões para melhorar ou inovar nas ações". O entrevistado 10 comentou "que precisa estar engajado em projetos sociais, ambientais, com projetos de energias sustentáveis e projetos sociais, principalmente", para ser um associado da Roteiros. O entrevistado 14 menciona que "há uma influência de forma indireta com a troca de informações e conhecimento que existe com outros hoteleiros".

A partir do exposto e de acordo com o entendimento sobre o pluralismo relacional, conforme definido por Shipilov et al. (2014), o mesmo ocorre somente com a REDE. O estudo realizado por Coppa e Sriramesh (2013) apresenta os funcionários como os stakeholders mais importantes dentro do processo de comunicação da RSC, o que difere do resultado obtido nesta tese, ou seja, os colaboradores não possuem consistência como fator quantitativo e são poucos mencionados nas evidências qualitativas. Essa disparidade pode estar relacionada ao fato das questões estratégicas ficarem centralizadas no nível da administração, enquanto que no estudo italiano os colaboradores eram responsáveis apenas pela difusão da informação.

Assim, como resultado da investigação sobre as estratégias coletivas de responsabilidade social corporativa de pequenas empresas, influenciadas pelo pluralismo relacional com seus distintos stakeholders, conclui-se que, por mais que as pousadas e hotéis se relacionem com distintos públicos, aquele que, de fato, influencia as ações de RSC é a Roteiros de Charme, ou seja, a própria rede.

No tópico sobre a influência dos diferentes tipos de pluralismo relacional nas estratégias coletivas de responsabilidade social corporativa de pequenas empresas buscou-se observar a ocorrência das relações multiplex, heterogeneous e overlapping. A primeira, relações multiplex, ocorre quando os mesmos atores mantêm múltiplos tipos de relações. Dessa forma, verificou-se com os entrevistados se existia algum tipo de relação comercial e que se tornou fornecedor, algum fornecedor cliente, ou algum cliente que passou a ser amigo.

Nesse aspecto, os resultados encontrados apontam que há múltiplos tipos de enfoques relacionais, pois foram citados vários exemplos de clientes que passaram a ser 
amigos dos donos das pousadas e hotéis. O entrevistado 23 cita o exemplo de hóspedes comuns que se tornaram amigos de verdade, como é o caso da atual presidente de um instituto social da cidade. A mesma, depois que se hospedou na pousada, se tornou amiga da proprietária e foi apresentada ao instituto por intermédio dela mesma. Outro exemplo é de clientes que se tornaram fornecedores. $\mathrm{O}$ entrevistado 16 citou assim: "tivemos uma cliente que se hospedou na pousada por conta da lua de mel e quando abriu uma empresa de cerimonial e protocolo acabou realizando diversos eventos na pousada".

A segunda relação é a heterogeneous que ocorre quando há conexões com outras pessoas de origens muito diferentes. Para investigar a questão questionaram-se os entrevistados se a pousada ou o hotel se relacionava ou fazia benchmarking com hotéis de outros países em relação às práticas de RSC. De uma forma sistemática a questão não ocorre, mas alguns proprietários das pousadas e hotéis, quando viajam para o exterior, procuram observar as melhores práticas e trazer para a realidade local. O entrevistado 12 confirma essa questão ao mencionar que "a gente viaja para os outros hotéis que têm o mesmo padrão para ver o que ele tem a oferecer para os clientes, que não fazemos, e a gente verifica se dá para adaptar". Alguns entrevistados comentaram que a rede é que faz este papel de verificar no exterior o que está sendo aplicado, como afirma o hotel 3 "não, somente a rede desenvolve este tipo de contato com outros hotéis de outros países".

E a última relação é a overlapping que é quando as relações ocorrem em redes fechadas, ou seja, com os mesmos atores. Para analisar essa ocorrência, verificaram se as pousadas e hotéis mantinham relações sempre com os mesmos stakeholders, identificados também na pesquisa. Desses, $40 \%$ afirmaram que mantêm uma relação fechada com os seus stakeholders, como afirma o entrevistado 7, que comenta "basicamente sim, buscamos trabalhar com um ciclo fechado". Essa afirmação das pousadas e hotéis terem uma rede fechada é questionável, pois pela característica do serviço em oferta, o relacionamento com os clientes, mesmo que tenham uma taxa de retorno elevada, é renovada, ou seja, não tem como serem sempre os mesmos clientes.

O mesmo ocorre com os fornecedores, pois as empresas podem ter fornecedores desde o início da operação, mas novos acabam surgindo ao longo do tempo, devido à necessidade de um novo produto ou até mesmo pelas negociações estabelecidas na rede. $\mathrm{O}$ entrevistado 10 confirma esse aspecto da troca de fornecedores ao mencionar que:

Às vezes algumas trocas são necessárias, porque os fornecedores não estão dando retorno, mas temos alguns bem antigos. Mas acredito que a relação de longo prazo é benéfica, pois se cria um vínculo e fica mais fácil de se negociar. Os funcionários são muito antigos, desde o início da operação há 17 anos. (Entrevistado 10) 
No contexto, $60 \%$ das pousadas e hotéis informaram que há alteração de algum stakeholder ao longo do tempo, como o entrevistado 21 afirmou, "alguns fornecedores são perenes e outros são sazonais". O entrevistado 16 também respondeu que

\begin{abstract}
procuramos trabalhar com fornecedores locais, mas alguns são de fora da cidade devido aos preços, pois o destino em que a pousada está situada é caro e isso repercute no preço dos produtos e serviços. Com isso a pousada acaba experimentando novos fornecedores, mas buscam ter um conjunto de fornecedores fixo, dentro do possível.
\end{abstract}

Com os relacionamentos identificados, procurou-se verificar se as relações com os stakholders afetavam as prioridades de práticas voltadas aos aspectos sociais, ambientais e econômicos. Alguns entrevistados responderam que a influência é da rede, como os entrevistados 6 e 9 afirmam que a rede acompanha as pousadas e hotéis através de visitas bianuais. Nas visitas, são feitos questionários e reavaliados na visita posterior no que se refere às práticas a que o hotel se propôs a modificar dentre outras questões e, ainda, são ministradas palestras para todos os funcionários com a presença ocasional de fornecedores. As visitas são de vistoria, mas apontam sugestões muito pertinentes e produtivas que acabam impactando na priorização do que desenvolver nas empresas. O entrevistado 22 menciona que "trocamos ideias com a rede a fim de verificar se não estão implantando algo que entre em conflito com a filosofia da rede. Além disso, verificam em nível local com os demais hotéis da região se a ação pensada já foi aplicada ou se seria algo inovador".

Por outro lado, outras pousadas e hotéis acreditam não sofrer influência de qualquer stakeholder, como é o caso do entrevistado 1 que comenta "não percebo interferência. Atitudes são feitas pelas constatações da pousada". O entrevistado 25 também confirma que não há influência, pois "o hotel é bem independente. Se o hotel quer fazer ele vai fazer e ponto. Vai desistir da ação se não tiver quem atenda a demanda (no caso dos fornecedores)".

Assim, tendo como base os estudos sobre as relações multiplex (Kuwabara, Luo \& Sheldon, 2010; Rogan, 2014; Tuuli, Koh \& Phua, 2012), relações heterogeneous (Gulati et al., 2010), relações overlapping (Gulatiet al., 2010; Kuwabara, Luo, \& Sheldon, 2010) e a influência nas estratégias coletivas de responsabilidade social corporativa de pequenas empresas apenas a variável multiplex gerou uma influência. Além disso, nas evidências qualitativas, apesar da variável multiplex também ter se destacado, verificou-se que esse tipo de relação mantida pelas pousadas e hotéis exerce pouca influência nas estratégias de RSC, remetendo sempre à rede como stakeholder que fomenta tais ações. 
Verificou que a intensidade da relação dos stakeholders com as pequenas empresas é um aspecto influenciador nas estratégias coletivas de responsabilidade social corporativa. E, diferentemente de outras menções em que aparecia apenas a rede como um stakeholder, surge como agente relevante a relação com fornecedores e clientes. A intensidade da relação está baseada nos estudos de laços os quais podem ser fortes, fracos ou ausentes (Granovetter, 1973) e, dependendo da intensidade, podem influenciar o comportamento estratégico, conforme estudos de Ranganathan e Rosenkopf (2014).

A intensidade da relação com o stakeholders influencia as estratégias coletivas de responsabilidade social corporativa de pequenas empresas. Esse aspecto foi verificado ao se questionar as pousadas e hotéis sobre a realização de alguma consulta ou troca de ideias com os stakeholders quando pensavam em desenvolver uma nova ação de RSC. Nesse caso, 28\% dos hoteleiros responderam que não realizam nenhuma consulta para novas ações, que tais questões ficam mais a cargo da administração da pousada e do hotel, justificando-se pelo fato da RSC já estar associada aos valores e à orientação do empresário (Del Baldo, 2012). O entrevistado 24 confirma essa posição ao dizer que "não realizamos nenhuma consulta. Caso haja alguma mudança um pouco mais drástica, e afetaria o andamento, a associação é comunicada, sim. Mas não é uma prática comum”. Outra posição igual é a do entrevistado 5, que afirma assim: "não é feita nenhuma consulta externa para novas ações, que é necessário, somente, um consenso entre os três proprietários que promovem a execução das ações”.

Em contrapartida, $72 \%$ das pousadas e hotéis costumam realizar consultas ou troca de ideias com algum stakeholder no que tange as novas ações de RSC. As respostas direcionaram para a maioria das consultas que são realizadas com a rede. Os hoteleiros mantêm um grupo no whatsapp a fim de trocarem ideias constantemente, sendo um dos aspectos mais mencionados pelos entrevistados. O entrevistado 3 corrobora a questão da consulta aos parceiros e inclui também a consulta aos clientes, mencionando, inclusive, algumas sugestões dos clientes para melhoria dos serviços, como por exemplo:

Um cesto para colocar as toalhas para troca diária, invés de colocar no chão; e um
cesto de lixo identificado para produtos orgânicos e outro seco, a ser disponibilizado
nos apartamentos. E também através de algumas capacitações que são fornecidas
pelo sindicato local, onde são implementadas melnorias para os colaboradores, como
por exemplo, camareiras que estão grávidas não podem ter acesso a produtos de
limpeza de banheiro, onde é necessário colocar duas funcionárias para fazer a
limpeza do apartamento. A funcionária grávida cuida da parte de troca de toalhas,
lençóis e organização do espaço, enquanto a outra funcionária faz a limpeza com o
uso dos produtos químicos. (Entrevistado 3)

Foi verificado na pesquisa se a intensidade do relacionamento com os diferentes stakeholders interferia na opinião que eles forneciam para o desenvolvimento de estratégias 
de RSC que o hotel desenvolvia. O entrevistado 19 apresenta a intensidade da relação como sendo importante com os hóspedes e fornecedores, alegando que:

\begin{abstract}
Alguns interfere sim, como hóspedes e fornecedores, que fizeram doações para projetos sociais, como instituto Iandê, como a oficina peixe boi e arte. A gente conseguiu vários patrocínios para a região através de pessoas que a gente se relaciona na pousada. Doações de máquinas de costura para a Fundação Peixe Boi e Arte, projetos ambientais financiados pela Fundação Toyota, distribuição de tonéis de lixo doados pela Braskem, e tantas outras coisas. Interfere bastante, alguns são pequenos fornecedores não interfere, mas com outros clientes e fornecedores já conseguimos bastante coisa para a região. (Entrevistado 19)
\end{abstract}

O entrevistado 15 argumenta que a intensidade da relação, principalmente com a rede é um aspecto importante, pois "quando se conhece uma pessoa e o negócio que ela tem se consegue verificar a conduta que ela terá. Consegue verificar boas práticas, atitudes”. Essa afirmação vem ao encontro com o trabalho de BarNir e Smith (2002), devido à força dos laços que influencia o estabelecimento de alianças. O que também é corroborado pelo entrevistado 25 ao mencionar que a intensidade na relação "é um fator importante, porque você tem a experiência e confiança do parceiro que já fez ou está fazendo algo neste sentido. E também a própria rede acaba vendo algumas questões para todos os associados, como negociação de placas solares".

Da mesma forma que a intensidade da relação à longevidade da mesma com os stakeholders é um aspecto influenciador nas estratégias coletivas de RSC. As relações estabelecidas pelas pousadas e hotéis podem ser analisadas com foco na relação com a rede, com os fornecedores, com os clientes e com outras instituições. Das 25 pousadas e hotéis, a média de tempo em que estão associadas a Roteiros de Charme é de 8 anos. Dessa amostra de associados, em torno de $40 \%$, isso acontece há mais de 10 anos na rede, como é o caso da fala do Entrevistado 14, um dos sócios fundadores e está na rede há 24 anos, enquanto apenas $16 \%$ está há 01 ano ou menos de associação. O entrevistado 17 exemplifica o tempo que está na rede ao afirmar que "sou muito nova na Roteiros de Charme, tenho 7 anos de pousada e vou fazer um ano de roteiros, sou uma baby roteiro".

A mesma questão da longevidade da relação pode ser verificada com os fornecedores. O tempo de parceria com os fornecedores em sua grande maioria é variado em cada empresa, mas é unanimidade que cada uma delas conta com relacionamentos sólidos com algum fornecedor, sendo que alguns deles desde o início da operação de cada pousada e hotel. $\mathrm{O}$ entrevistado 4 confirma essa questão ao mencionar que

a relação com alguns fornecedores já tem algum tempo. As relações são sólidas. Dificilmente possuímos fornecedores novos e todos os que temos são antigos, temos fornecedores de 5, 6, 7, 10 anos que fornecem para o hotel. Que se adequaram, que 
sabem o padrão de exigência e funcionam de forma coerente. É uma história longa, é um relacionamento bem estável.

Alguns novos fornecedores acabam surgindo em virtude da necessidade de fornecimento de novos produtos/serviços, pela questão de preço e, até mesmo, devido à dificuldade de encontrar certos fornecedores que atendam as localidades. Essa última questão é pontuada pelo Entrevistado 25 afirmando que

pela localização do hotel não ser tão urbana nós possuímos uma dependência de fornecedores. Você acaba não podendo ter uma rotatividade muito grande de fornecedores, então você acaba por conta disso tendo uma certa relevância em termo de valores e prazos com eles.

Em relação aos clientes, pelo fato das pousadas e dos hotéis focarem no lazer, o perfil deles é na sua grande maioria de pessoas físicas. Por isso, a quantidade de novos clientes que se hospedam nas empresas é muito grande. Apesar disso, há clientes fiéis que retornam várias vezes ao longo do ano e também por muitos anos. O entrevistado 1 citou um cliente que era fazendeiro da região e que se hospedava na pousada pelo menos uma vez por mês. A relação durou por 3 anos até que ele se mudou para Goiás. O entrevistado 10 menciona que "o índice de retorno é surpreendente. Inclusive os hóspedes mais antigos são os meus melhores amigos. Há hóspedes que em 17 anos já vieram mais de 20 vezes na pousada. A gente tem uma taxa de retorno acima de $60 \%$, então é muito duradoura e legal”.

Sobre as demais instituições, o tempo de relacionamento também é a longo prazo. A maioria das pousadas e dos hotéis são associados aos sindicatos e entidades do setor de turismo e hotelaria, bem como dos sindicatos patronais, desde o início da operação de cada empresa. Em outras entidades, como Ongs e parcerias comerciais, as empresas também são associadas há mais de um ano, como é o caso do entrevistado 25, que diz assim: "participo de uma entidade que reúne os mais exclusivos hotéis, resorts, pousadas e operadoras do Brasil há 3 anos". O entrevistado 23 também está há 3 anos no conselho de um instituto social. Já o entrevistado 13 está no conselho do hospital local há 4 anos.

Percebe-se que os relacionamentos mantidos pelas pousadas e hotéis, com os distintos stakeholders são, na sua grande maioria, de médio a longo prazo. A respeito do tempo de relacionamento com esses atores, pergunta-se se interferia, na opinião deles, o desenvolvimento de estratégias de RSC, desenvolvidos pelo hotel, não houve uma unanimidade nas respostas. Mesmo assim, alguns entrevistados acham que o fator longevidade acaba não interferindo. $\mathrm{O}$ entrevistado 2 , a respeito desse fato, comenta que:

O hotel está sempre aberto a novas sugestões, independentemente do tempo. Até o próprio cliente que se hospeda a primeira vez e dá uma sugestão relevante e ela vai melhorar a gente está aceitando. Não necessariamente seja um fornecedor ou a rede, 
o hotel tem a característica de aceitar e reconhecer sugestões de todos, clientes, funcionários, fornecedores, independente do tempo. Isso se soma. (Entrevistado 2)

Uma visão complementar também é a do entrevistado 21 , que considera o tempo assim:

\begin{abstract}
o tempo é um fator para se estreitar laços, mas que não interfere na qualidade do serviço. Por ser uma ilha, deve haver eficiência e qualidade no produto". Outros entrevistados acreditam que o tempo seja um aspecto relevante, como o entrevistado 20 ao afirmar que "o tempo de relacionamento traz uma segurança na parceria e ajuda no contexto local, pois estão no interior e tudo é mais complicado". O entrevistado 16 também concorda com esse aspecto ao mencionar que "o tempo influencia diretamente. Com os demais parceiros se buscam mais informações.
\end{abstract}

As entrevistas evidenciam que não são todos os stakeholders que influenciam as estratégias coletivas de RSC, mas se destacou a longevidade da relação entre os associados e também entre as pousadas e hotéis com a própria rede. Essa inferência reforça os demais resultados encontrados na pesquisa sobre o poder influenciador da rede no contexto.

Assim, verificaram-se as estratégias coletivas de responsabilidade social corporativa de pequenas empresas que são influenciadas pela longevidade da relação com os stakeholders (Krackhardt, 1992). Esse aspecto é muito relevante, visto que na teoria não se encontraram muitos estudos que mencionasse a influência do tempo das relações sobre as organizações e muito menos para as redes.

\title{
5. CONSIDERAÇÕES FINAIS
}

O presente estudo também buscou analisar a relação das pequenas empresas a partir do pluralismo relacional com seus atores e verificar se existe influência desses atores no desenvolvimento de estratégias de RSC pelas pequenas empresas. Dessa forma, entende-se que algumas empresas possuem planejamento formal das ações a serem desenvolvidas no âmbito socioambiental, enquanto outras acabam desenvolvendo de maneira informal. Porém, independente da empresa, as relações estabelecidas com a rede são, de fato, a grande influenciadora das estratégias coletivas de responsabilidade social corporativa. A partir da direção da rede, são emanadas as estratégias institucionais de RSC que devem ser implementadas de forma geral, além da relação indireta com os associados, já que, em ambientes informais, há trocas de informações e melhores práticas no âmbito socioambiental que influenciam o desenvolvimento de outras ações.

Por fim, se evidenciam os aspectos relacionados ao tipo, intensidade e longevidade da relação que influenciam as diferentes estratégias de RSC. Dentre os diversos tipos de pluralismo relacional, o mais evidente foi o multiplex, porém esse não exerce 
influência em relação à RSC, ao passo que a intensidade e a longevidade são fatores determinantes para o desenvolvimento das estratégias de RSC.

$\mathrm{O}$ estudo possui limitações quanto ao aspecto metodológico devido a dois aspectos. O primeiro deles, de acordo com o estudo, contemplou a análise de uma única rede do segmento hoteleiro. Portanto, os resultados limitam-se aos aspectos encontrados nesse contexto; o outro, refere-se à possibilidade de visões parciais dos respondentes de pesquisa de natureza qualitativa.

Por fim, na perspectiva operacional, a dificuldade da pesquisa foi o acesso a todas as pousadas e hotéis que integram a rede, resultando no tamanho da amostra. Outro aspecto se refere ao fato de que os dados primários foram coletados apenas com um gestor de cada empresa. Apesar desse aspecto a pesquisa foi relevante pelos resultados obtidos e conclusões atingidas.

Como possíveis trabalhos futuros, a primeira oportunidade é desenvolver outros estudos que utilizem distintos métodos, como a Análise Qualitativa Comparativa (QCA), que através da análise booleana identifica padrões de variáveis independentes de associados a uma determinada variável dependente. A QCA permite valores entre 0 e 1. Esses valores podem representar probabilidades de associação em um conjunto de valores para uma determinada variável.

Um estudo longitudinal pode ser desenvolvido com o mesmo objeto empírico para analisar se, com o passar do tempo, os mesmos resultados serão encontrados, tendo em vista que a rede continua em processo de expansão e novos associados acabam ingressando a cada ano. Por fim, a pesquisa empírica aqui realizada foi direcionada para o setor de hotelaria, que pode ser complementado com análises em outras redes do mesmo segmento, mas em diferentes contextos, bem como a realização da mesma pesquisa em setores distintos.

\section{REFERÊNCIAS}

Alvesson, M., Ashcraft, K. L. \& Thomas, R. (2008). Identity matters: reflections on the construction of identity scholarship in organization studies. Organization, London, 15(1), 528.

Ashforth, B. E. (1998). Becoming: how does the process of identification unfold? In: Whetten, D. A. \& Godfrey, P. C. (Ed.). Identity in organizations: developing theory through conversations. Thousand Oaks, California: Sage, 213-222. 
Ashforth, B. E. \& Mael, F. A. (1989). Social identity theory and organization. Academy of Management Review, Mississippi, 14(1), 20-39.

Astley, W. G. (1984). Toward an appreciation of collective strategy. Academy of Management Review, Mississippi, 9(3), 526-535.

Astley, W. G. \& Fombrun, C. J. (1983). Collective strategy: social ecology of organizational environments. Academy of Management Review, Mississippi, 8(4), 576-587.

Bansal, T. \& Desjardine, M. (2015). Don't confuse sustainability with CSR. Ivey Business Journal, London, Ontario. Retrieved november, 10, 2016, from http://iveybusinessjournal.com/dont-confuse-sustainability-with-csr/

Bardin, L. (1977). Análise de conteúdo. Lisboa: Edições 70.

Barnett, W. P., Mischke, G. A. \& Ocasio, W. (2000). The evolution of collective strategies among organizations. Organization Studies, Berlin, 21(2), 325-354.

Barnir, A. \& Smith, K. (2002). Interfirm alliances in the small business: the role of social networks. Journal of Small Business Management, Morgantown, Wa. Va., 40(3), 219-232.

Benson, J. K. (1975). The interorganizational network as a political economy. Administrative Science Quarterly, [Ithaca, N.Y.], 20(2), 229-249.

Blindheim, B. \& Langhelle, O. (2010). A reinterpretation of the principles of CSR: a pragmatic approach. Corporate Social Responsibility and Environmental Management, Chichester, West Sussex, 17(2), 107-117.

Brandenburger, A. M. \& Nalebuff, B. J. (1995). The right game: use game theory to shape strategy. Harvard Business Review, Boston, 73(4), 57-71.

Collis, J. \& Hussey, R. (2005). Pesquisa em administração: um guia prático para alunos de graduação e pós-graduação. Porto Alegre: Bookman.

Coppa, M. \& Sriramesh, K. (2013). Corporate social responsibility among SMEs in Italy. Public Relations Review, College Park, Md., 39(1), 30-39.

Creswell, J. W. (2010). Projeto de pesquisa: métodos qualitativo, quantitativo e misto. Porto Alegre: Artmed.

Davis, K. (1973). The case for and against business assumption of social responsibilities. Academy of Management Journal, Champaign, Ill., 16(2), 312-322.

Del Baldo, M. (2012). Corporate social responsibility and corporate governance in Italian SMEs: the experience of some "spirited businesses"'. Journal of Management and Governance, Dordrecht, 16(1), 1-36.

Doh, J. P. \& Tashman, P. (2014). Half a world away: the integration and assimilation of corporate social responsibility, sustainability, and sustainable development in business school 
curricula. Corporate Social Responsibility and Environmental Management, Chichester, West Sussex, 21(3), 131-142.

Flick, U. (2009). Introdução à pesquisa qualitativa. (3a ed.). Porto Alegre: Artmed.

Gatti, L. \& Seele, P. (2014). Evidence for the prevalence of the sustainability concept in European corporate responsibility reporting. Sustainability Science, [S.l.], 9(1), 89-102.

Gil, A. C. (2010). Como elaborar projetos de pesquisa. São Paulo: Atlas.

Gioia, D. A., Price, K. N., Hamilton, A. L. \& Thomas, J. B. (2010). Forging an identity: an insider- outsider study of processes involved in the formation of organizational identity. Administrative Science Quarterly, [Ithaca, N.Y.], 55(1), 1-46.

Gioia, D. A., Schultz, M. \& Corley, K. G. (2000). Organizational identity, image, and adaptive instability. Academy of Management Review, Mississippi, 25(1), 63-81.

Granovetter, M. S. (1973). The strength of weak ties. American Journal of Sociology, Chicago, 78(6), 1360-1380.

Gulati, R., Kilduff, M., Stan Li, Shipilow, A. \& Tsai, W. (2010). The relational pluralism of individuals, teams and organizations. Academy of Management Journal, Champaign, Ill., 53(4), 914-915.

Hanleybrown, F., Kania, J. \& Kramer, M. (2012). Channeling change: Making collective impact work. Stanford Social Innovation Review, Stanford.Retrieved november, 14, from https://ssir.org/articles/entry/channeling_change_making_collective_impact_work

Herrmann, K. K. (2004). Corporate social responsibility and sustainable development: The European Union initiative as a case study. Indiana Journal of Global Legal Studies, Bloomington, 11(2), 205-232.

Kania, J. \& Kramer, M. (2011). Collective impact. Stanford Social Innovation Review, Stanford, 9(1), 36-41.

Krackhardt, D. (1992). The strength of strong ties: the importance of philos in organizations. In: Nohria, N. \& Eccles, R. (Ed.). Networks and organizations: structure, form, and action. Boston: Harvard Business School Press, 216-239.

Kuwabara, K., Luo, J. \& Sheldon, O. (2010). Multiplex exchange relations. In: Thye, Shane R. \& Lawler, Edward J. (Ed.). Advances in group processes 27. Bingley, UK: Emerald Group Publishing, 239-268.

Metcalf, L. \& Benn, S. (2012). The corporation is ailing social technology: creating a "fit for purpose" design for sustainability. Journal of Business Ethics, Dordrecht, 111(2), 195-210.

Morhardt, J. E. (2010). Corporate social responsibility and sustainability reporting on the Internet. Business Strategy and the Environment, Bradford, 19(7), 436-452. 
Nielsen, R. P. (1988). Cooperative strategy. Strategic Management Journal, Sussex, 9(5), 475-492.

Porter, M. \& Kramer, M. (2011). Creating shared value; How to reinvent capitalism: and unleash a wave of innovation and growth. Harvard Business Review, Boston, 89(1/2), 63-70.

Provan, K., G., Fish, A. \& Sydow, J. (2007). Interorganizational networks at the network level: A review of the empirical literature on whole networks. Journal of Management, Thousand Oaks, 33(3), 479-516.

Rahman, S. (2011). Evaluation of definitions: ten dimensions of corporate social responsibility. World Review of Business Research, Melbourne, 1(1), 166-176.

Ranganathan, R. \& Rosenkopf, L. (2014). Do ties really bind? The effect of knowledge and commercialization networks on opposition to standards. Academy of Management Journal, Champaign, Ill., 57(2), 515-540. Retrieved november, 10, 2016 from http://dx.doi.org/10.5465/amj.2011.1064

Rogan, M. (2014). Executive departures without client losses: the role of multiplex ties in exchange partner retention. Academy of Management Journal, Champaign, Ill., 57(2), 563584. Retrieved november, 10, 2016, from http://dx.doi.org/10.5465/amj.2011.1049

Roteiros de Charme (2016). Home. Rio de Janeiro. Recuperado em 13, novembro, 2016, de http://www.roteirosdecharme.com.br

Roth, A. L., Wegner, D., Antunes Junior, J. A. A \& Padula, A. D. (2012). Diferenças e interrelações dos conceitos de governança e gestão de redes horizontais de empresas:

contribuições para o campo de estudos. Revista de Administração, São Paulo, 47(1), 112-123.

Sharma, S. K. \& Mehta, S. (2012). Where do we go from here? Viewing corporate social responsibility through a sustainability lens. The Journal Contemporary Management Research, [S.1.], 6(2), 69-76.

Shipilov, A., Gulati, R., Kilduff, M., Stan Li \& Tsai, W. (2014). Relational pluralism within and between organizations. Academy of Management Journal, Champaign, Ill., 57(2) 449459.

Soares, G. M. P. (2004). Responsabilidade social corporativa: por uma boa causa!?. RAE Eletrônica, São Paulo, 3(2), 1-15. Recuperado em 10, novembro, 2016, de http://rae.fgv.br/sites/rae.fgv.br/files/artigos/10.1590_S1676-56482004000200012.pdf

Strand, R., Freeman, R. E. \& Hockerts, K. (2015). Corporate social responsibility and sustainability in Scandinavia: An overview. Journal of Business Ethics, Dordrecht, 127(1), 115 .

Tajfel, H. \& Turner, J. C. (1985). The social identity theory of intergroup behaviour. In: Worchel, S. \& Austin, W. G. (Ed.). Psychology of intergroup behaviour,(2nd ed.). Chicago: Nelson-Hill, 7-24. 
Tuuli, M. M., Koh, T. Y. \& Phua, F. (2012). Relational pluralism in project settings: towards a research agenda. Montreal, Canada. Retrieved november, 10, 2016, from https://dspace.lboro.ac.uk/dspace-jspui/bitstream/2134/11838/3/CIB\%20Paperv7.2.pdf

Van Marrewijk, M. (2003). Concepts and definitions of CRS and corporate sustainability: between agency and communion. Journal of Business Ethics, Dordrecht, 44(2), 95-105.

Voss, C., Tsikriktsis, N. \& Frohlich, M. (2002). Case research in operations management. International Journal of Operations and Production Management, Bradford, 22(2), 195-219.

Williams, O. F. (2014). CSR: will it change the world? Hope for the future: an emerging logic in business practice. Journal of Corporate Citizenship, Sheffield, UK, 53, 9-26.

SILVA, P. M. (2018). Pluralismo relacional como influenciador de ações de responsabilidade social corporativa de uma rede de pequenas empresas do setor hoteleiro. Revista de Turismo Contemporâneo, 6(2), 315-338. 